\title{
Molar Tooth Sign in an Ischemic Stroke Patient: Could It Be Asymptomatic Joubert Syndrome?
}

\author{
İskemik Inmeli Hastada Molar Diş Görüntüsü; Asemptomatik Joubert Sendromu \\ Olabilir mi?
}

Ersin Kasım Ulusoy', Şule Bilen², Fikri Ak²

'Department of Neurology, Develi Hatice Muammer Kocatürk Hospital, Kayseri, Turkey 2Department of Neurology, Ankara Numune Training and Research Hospital, Ankara, Turkey

\section{ABSTRACT}

Introduction: Joubert syndrome is an autosomal recessive disease that is characterized by hypotonia, ataxia, and hyperpnea episodes. A hypoplastic cerebellar pedicle and complete or partial absence of the vermis are basic radiological findings and the cause of fourth ventricle deformity. These findings cause 'molar tooth signs' on magnetic resonance (MRI).

Case Report: A 69-year-old male patient who had acute left hemiparesis was admitted to the emergency department. Conventional MRI revealed hypoplasia of the cerebellar pedicle and vermis. In addition, an acute ischemic lesion that was determined by the limitation of diffusion at the level of the pons was noticed. Molar tooth sign in the MRI might be in the course of Joubert syndrome (JS). Due to this finding, other diagnostic tests were performed for the diagnosis of JS. In conclusion, the patient was diagnosed as asymptomatic Joubert syndrome and newly diagnosed pons infarction.

Conclusion: In this case report, we present an asymptomatic Joubert syndrome patient with MRI and ophthalmic findings who was admitted to the emergency department with acute stroke.

Keywords: Asymptomatic Joubert syndrome, molar tooth sign Received: 25.08.2013 Accepted: 04.02.2014

\section{ÖZET}

Giriş: Joubert Sendromu otozomal resesif geçiş gösteren, hipotoni, ataksi, epizodik hiperpne nöbetleriyle seyreden bir hastalıktır. Temel radyolojik bulgular; vermisin tam veya parsiyel yokluğu, hipoplastik serebeller pediküller ve buna bağlı 4 . ventrikül deformitesidir. Manyetik rezonans (MRI) görüntülerde 'molar diş' görünümüne neden olur.

Olgu Sunumu: Altmış dokuz yaşındaki erkek hasta acil servisimize akut sol hemiparazi kliniği ile başvurdu. Çekilen konvensiyonel kranial MRI'da serebellar hemisferler ve vermis hipoplazikti. Ayrıca pons seviyesinde diffüzyon kısıtlanması gösteren akut iskemik lezyon dikkati çekti. MRl'daki molar diş görüntüsü Joubert Sendromu (JS) seyrinde olabileceğinden tanıya yönelik tetkikler yapıldı. Hasta elde edilen bulgularla asemptomatik JS ve yeni tanı pons enfarktı olarak değerlendirildi.

Sonuç: Bu olgu sunumunda acil kliniğine akut inme kliniği ile başvuran takiplerinde Asemptomatik Joubert Sendromu tanısı alan hastanın göz ve MRI bulguları ile birlikte sunduk.

Anahtar Kelimeler: Asemptomatik joubert sendromu, molar diş görüntüsü

Geliş Tarihi: 25.08.2013 Kabul Tarihi: 04.02.2014

\section{Giriş}

Joubert Sendromu (JS) otozomal resesif geçiş gösteren, hipotoni, ataksi, epizodik hiperpne nöbetleriyle seyreden serebellum ve beyin sapını etkileyen bir hastalıktır (1). Hastalığın prevelansı 100.000 doğumda bir görülmesine rağmen klinik çok değişken olduğu için tanı konulması zordur. Klinik olarak anormal göz hareketleri, nistagmus, hiperpne-apne epizodları ve mental-motor gelişme geriliği izlenir (2-5). Semptomlar erken çocukluk çağında başlar. JS'nin belirleyici nöroradyolojik bulguları; serebellar vermisin tam veya parsiyel yokluğu, pedinküler hipoplazi ve buna bağlı gelişen 4. ventrikülde lobulasyon ve genişlemedir. Beyin sapı isthmus bölgesinin disgenezisine bağlı ponto mezansefalik birleşkede uzama, incelme ve interpediküler fossada 


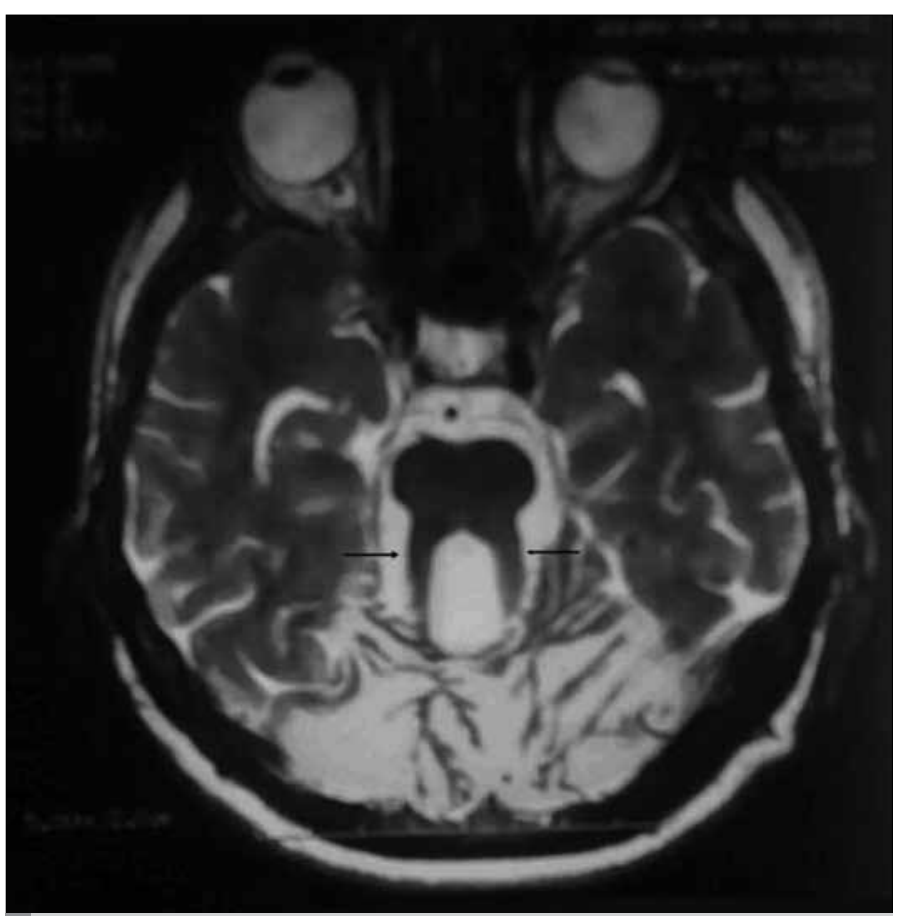

Şekil 1. T2 sekansda görülen molar diş görünümü ve serebellar hipoplaziye ait bulgular

derinleşme izlenir. Bu bulgular aksiyal kranial manyetik rezonans (MRI) görüntülerde 'molar diş' görünümünü oluşturur (6-7).

Bizim olgumuz ise erişkin yaşta olması ve serebrovaskuler olay tanısı ile hospitalize edilip takip edildiği sırada yapılan konvensiyonel kranial MRI görüntülemede tipik olarak molar diş görünümü saptanması ve JS'de görülen klinik bulguların olmaması nedeniyle asemptomatik seyirli JS olarak literatür eşliğinde yazmaya değer bulduk.

\section{Olgu Sunumu}

Atmışdokuz yaşında erkek hasta acil servise yeni başlangıçlı yürüme bozukluğu şikayeti ile getirildi. Ilk değerlendirmede ölçülen kan basıncı 170/85 mmHg, kalp ritmikti ve atım hızı 76/ dk idi. Sistemik muayenesinde hafif solunum sıkıntısı mevcuttu, dinlemekle ekspiryum uzamıştı ve solunum sayısı 15/dk idi. Nörolojik muayenesinde; bilinç açık kooperasyon kısıtlıydı. Motor muayenede sol üst ve alt ekstremitede silik motor güçsüzlüğü tesbit edildi. Yürüyüşü ataksik olarak izlendi. Duyu ve serebellar testlere koopere olamadı. Yapılan göz muayenesinde sağ göz hareketi her yöne kısıtlı iken, sol göz fiks dışa deviye idi ve solda pitozis izlendi.

Laboratuar incelemesinde; Lökosit;7500/mm³ Hb:12,3 g/dL, AST; $27 \mathrm{mu} / \mathrm{mL}$ (N 13-41), ALT $33 \mathrm{mu} / \mathrm{mL}$ (N 7-35), BUN:18 mg/dL (N 7-25), Kreatinin: 1,1 mg/dL (N 0,84-1,25) idi. Elektrokardiografik (EKG) incelemesinde normal sinüs ritmi olarak değerlendirildi. Ön-arka akciğer grafisinde kardiyotorasik oran artmıştı. Acil servisde çekilen beyin tomografisinde akut patolojiye rastlanmadı.
Özgeçmişinde diyabet ve hipertansiyonun olduğu ve bu hastalıkları ile ilgili ilaçlar kullandığı öğrenildi. Çekilen diffüzyon ve konvensiyonel kranial MRI'da serebellarhemisferlerve vermis hipoplazikolarakizlendi (Şekil 1). Superior serebellar pedinküller posteriora doğru elongeydi. Medüllooblangata pons bileşkesi düzeyinde, santral kesimde, T1A sekansta hipo, T2A sekansta hiperintens sinyal değişikliği gösteren diffüzyon ağırlıklı görüntülemede diffüzyon kısıtlanması gösteren akut iskemik lezyon dikkati çekti. Böylelikle klinik ve laboratuar bulgular ışığında hastaya akut serebrovasküler olay tanısı konularak takip ve tedavi edilmeye başlandı. MRI'daki molar diş görüntüsü JS ve JS ile ilişkili hastalıklar seyrinde olabileceğinden, bu hastalıkların ayırıcı tanısı ve eşlik edebilecek multiorgan tutulumu açısından ileri ek tetkikler ve konsultasyonlar istendi. Hastaya çekilen abdominal ve üriner ultrasonografide (USG) karaciğer veya böbreğe ait patoloji saptanmadı. Yapılan göz hastalıkları konsültasyonunda göz bulguları beyinsapı vaskuler olaya bağlandı. Optik disk ve diğer retinal yapılar doğal olarak değerlendirildi. İskemik inme etyolojiye yönelik yapılan karotis-vertebral doppler USG'de stenoz bulgusu yoktu ve ekokardiografisinde sol ventrikül hipertrofisi vardı. Asemptomatik JS ve yeni tanı pons enfarktı olarak değerlendirilen hastanın medikal tedavisi düzenlendikten sonra önerilerle taburcu edildi.

\section{Tartışma}

Joubert sendromu ilk kez 1969 yılında Marie Joubert ve arkadaşları tarafından tanımlanan otozomal resesif geçişli nadir bir sendromdur. Yapılan çalışmalarda kromozom 9q, 11p ve $6 q$ mutasyonları gösterilmekle beraber hastalığın moleküler temeli tam olarak bilinmemektedir (1). Son yıllarda X'e bağlı resesif ve otozomal dominant vakalar da bildirilmiştir (4).

Klinik olarak anormal göz hareketleri, nistagmus, hiperpne-apne epizodları, hipotoni ve mental motor gelişme geriliği gözlenir $(2,3)$. En sık rastlanan göz bulguları horizontal ve vertikal planda izleyici göz hareketlerinde yavaşlama, okülomotor apraksi, vestibülo-oküler reflekste azalma, görme bozuklukları, okuler kolobom, Leberin herediter optik atrofisi, retinal distrofi, görme kaybı, pitozis, strabismus ve nistagmustur. Nistagmus sıklıkla rotatuar karakterdedir $(3,4)$. Dilde ritmik protrüzyon, oksipital meningoensefalosel, polidaktili, nefronofitizis veya böbreğin kistik displazisi, hepatik fibrozis, bradikardi kalpte üfürüm klinik bulgulara eşlik edebilir. Uzun dönem takiplerde mental retardasyon bulguları ortaya çıkabilir $(3,4,5)$. Bizim olgumuzda JS düşündürecek klinik ve laboratuar bulgusu yoktu. Literatür taramasında ileri yaşta klinik bulgu vermeden asemptomatik olarak seyreden izole molar diş görüntüsü bildirimine rastlanmadı.

Joubert Sendromunda genetik belirleyici özellikler değişken fenotipe sahip olduğu için tanı koymak güçtür. Klinik hipotoni, ataksi ve psikomotor gecikme, tanı koymada yetersiz spesifikliğe sahip olduğundan MRı bulguları halen en önemli tanı kriteridir (6). Ortalama tanı koyma yaşı 33 aydır. Radyolojik olarak vermisin tam veya kısmi yokluğu, hipoplastik serebeller pedinküller ve buna bağlı oluşan 4. ventrikül deformitesidir. Ponto mezansefalik 
bileşkede uzama, incelme ve interpedinküler fossada derinleşme izlenir $(6,7)$. Ayrıca vermis hipoplazisine bağlı olarak serebeller pedinküllerde kalınlaşma ve 4. venrikülde lobulasyon ve genişleme görülür. Bu üç bulgu MRl'da molar diş görünümünü oluşturur (7). Bizim olgumuzda da MRI'da serebellar hipoplazi ve molar diş görüntüsü vardı.

Molar diş görüntüsü JS için spesifik değildir. JS subtiplerinde ve JS ile ilişkili hastalıklarda (Serebello-okulo-renal Sendrom, Debakan-Arima Sendromu, Varadi- Papp Sendromu, Malta Sendromu ve SeniorLoken Sendromu gibi) molar diş görüntüsü olur. JS'nin altı subgrub tipi vardır. Pür JS, Oküler bulgularla seyreden JS, Renal bulgularla seyreden JS, Okülo-renal bulgular ile seyreden JS, Hepatik bulgularla seyreden JS, Orofasial bulgularla seyreden JS. COACH Sendromlu hastada bilateral kolobom, hepatik fibrozis ve renal kalsifikasyon görülür. Varadi-Papp Sendromunda polidaktili, Y şeklinde metakarpal kemik, yarık damak dudak, dilde hamartom ve vermian hipoplazi olur. Debakan-Arima sendromunda Leber'in herediter optik atrofisi ve kistik karaciğer, Senior-Loken sendromunda Leberin herediter optik atrofisi, retinitis pigmentaoza ve juvenil nefronofitizis olur. Malta sendromunda oksipital ensefalosel, hidrosefali ve renal kist görülür $(9,10)$. Bu sendromlarda molar diş görüntüsü klinik bulgularla birlikte olabileceği bildirilmiş̧ir.

Bizim olgumuzda erken dönemde ortaya çıkan solunum sıkıntısı, hipotoni bulgusu, aile öyküsü, orta hat defektleri, kardiyak (özelikle atrial septal defekt) renal ve hepatik bulguların olmaması nedeni ile erken çocukluk çağında görülen JS ve JS ile ilişkili hastalıklardan uzaklaşıldı. Hastadaki mevcut solunum sıkıntısı uzun yıllar sigara kullanım öyküsü olduğundan edinsel akciğer hastalığına bağlandı. Olgumuzun anamnezinde önceye ait göz hareket bozukluğu öyküsü olmaması ve muayenesindeki göz bulgularını açıklayacak pons iskemi bulgusu olması da çocukluk çağının JS'den bizi uzaklaştırdı.

\section{Sonuç}

Bu olgu ışığında kranial MRI'da JS için tipik olan molar diş görünümünün saptanması ve serebellar hipoplazisinin olması, çoçukluk döneminde ortaya çıkması beklenen klinik bulguların olmaması nedeni ile hastada insidental olarak saptanan bu MR bulgularının asemptomatik seyir gösterebileceğini literatür bilgileri ile birlikte sunduk.

Informed Consent: Patient consent was taken.

Peer-review: Externally peer-reviewed.
Author Contributions: Concept-Ş.B., F.A.; Design - E.K.U.; Supervision - E.K.U., S..B.; Materials - E.K.U.; Data Collection and/or Processing E.K.U.; Analysis and/or Interpretation - E.K.U., F.A.; Literature Review - E.K.U., Ş.B.; Writer - E.K.U.; Critical Review - Ş.B., F.A.

Conflict of Interest: The authors declared no conflict of interest.

Financial Disclosure: The authors declared that this study has received no financial support.

Hasta Onamı: Yazılı hasta onamı bu olguya katılan hastadan alınmıştır.

Hakem Değerlendirmesi: Dış bağımsız.

Yazar Katkıları: Fikir - Ş.B., F.A.; Tasarım - E.K.U.; Denetleme - E.K.U., Ş.B.; Malzemeler - E.K.U.; Veri toplanması ve/veya işlemesi - E.K.U.; Analiz ve/veya yorum - E.K.U., F.A.; Literatür taraması - E.K.U., S..B.; Yazıyı yazan - E.K.U.; Eleştirel İnceleme - Ş.B., F.A.

Çıkar Çatışması: Yazarlar çıkar çatışması bildirmemişlerdir.

Finansal Destek: Yazarlar bu çalışma için finansal destek almadıklarını beyan etmişlerdir.

\section{Kaynaklar}

1. Parisi MA, Doherty D, Eckert ML, Shaw DW, Ozyurek H, Aysun S, et al. AHI1 mutations cause both retinal dystrophy and renal cystic disease in Joubert syndrome. J Med Genet 2006; 43: 334-9. [CrossRef]

2. Chance PF, Cavalier L, Satran D, Pellegrino JE, Koenig M, Dobyns WB. Clinical nosologic and genetic aspects of Joubert and related syndromes. J Child Neurol 1999; 14: 660-6. [CrossRef]

3. Joubert M, Eisenring JJ, Robb JP, Andermann F. Familial agenesis of the cerebellar vermis. A syndrome of episodic hyperpnea, abnormal eye movements, ataxia and retardation. Neuro-logy 1969; 19: 813-25. [CrossRef]

4. Tusa RJ, Hove MT. Ocular and oculomotor signs in Joubert syndrome. J Child Neurol 1999; 14: 621-7. [CrossRef]

5. Steinlin M, Schmid M, Landau K, Boltshauser E. Follow-up in children with Joubert's syndrome. Neuropediatrics 1997; 28: 204-11. [CrossRef]

6. Quisling RG, Barkovich AJ, Maria BL. Magnetic resonance imaging features and classification of central nervous system malformations in Joubert syndrome. J Child Neurol 1999; 14: 628-35. [CrossRef]

7. McGraw P. The molar tooth sign. Radiology 2003; 229:671-2. [CrossRef]

8. Singh P, Goraya JS, Saggar K, Ahluwalia A. A report of Joubert syndrome in an infant, with literature review. J Pediatr Neurosci 2011; 6: 44-7.

9. Gleeson JG, Keeler LC, Parisi MA, Marsh SE, Chance PF, Glass IA, et al. Molar tooth sign of the midbrain-hindbrain junction: Occurrence in multiple distinct syndromes. Am J Med Genet A 2004; 125A: 125-34. [CrossRef]

10. Brancati F, Dallapiccola B, Valente EM. Joubert Syndrome and related disorders. Orphanet J Rare Dis 2010; 5: 20. [CrossRef] 